\title{
THE ITALIAN INDUSTRY/ENTERPRISE 4.0 PLAN: EX-ANTE IDENTIFICATION OF POTENTIAL BENEFICIARIES AND EX-POST ASSESSMENT OF THE USE OF INCENTIVES
}

\author{
GIULIO PERANI, STEFANO COSTA AND STEFANO DE SANTIS \\ DOI: $10.22163 /$ fteval.2019.334
}

\section{INTRODUCTION}

$\mathrm{T}$

he Italian Institute of Statistics (ISTAT) in addition to its role as member of the EU statistical system - i.e. official provider of economic and social statistical data and indicators - is also the Italian largest public research institution in charge of undertaking economic policy evaluation. The launching in 2016 by the Italian Ministry of Economic Development (MISE) of an innovative program of industrial policy, with a strong focus on the support of the digitalisation of Italian firms, has given ISTAT a unique chance to test original analytical and policy evaluation methodologies.

By following the German model of an Industry 4.0 platform (Rüßmann et al. 2015; ZEW 2015), MISE has developed a policy to support the digital transformation of the Italian business sector (National Plan "Industry 4.0", eventually become "Enterprise 4.0"), so acting more as a process enabler than a leading actor. The key measure of such policy is, in fact, an increase of the depreciation allowance for investment in machinery. According to this incentive scheme, the depreciation allowance, i.e. the amount a business can reduce its profit by when taxes are calculated, will be a percentage of the $140 \%$ (rather than $100 \%$ ) of the purchase cost of industrial equipment, which will increase to $250 \%$ if investing in digitally connected equipment.

The nature of such measure has forced policy makers to develop new methods of ex-ante and ex-post policy assessment, as the influence of public incentives on firms' investments in a given fiscal year can be appraised only after the process of financial reporting is finalised and the tax statements filed by the concerned firms (i.e. at least six months after the end of the year), so that the feedbacks are available to policy-makers more than two years after the launching of the incentive policy.

The issue discussed in this study is to what extent a new set of integrated microdata developed at ISTAT, combining statistical and administrative (mostly fiscal) sources, could help (a) to identify, ex-ante, the potential beneficiaries of the tax incentives and (b) to assess, ex-post, the degree of success of such policy measures.

As the exercise has been limited to a single incentive, implemented over a two-year period, only cross sectional data are available which do not allow for a proper modelisation of the relationship between potential and actual beneficiaries. Nevertheless, a comparison between these two sub-populations of firms will highlight, beyond the overlapping rate, similarities and differences which could be used both for a fine tuning of the policy measures under evaluation and for improving an ex-ante identification of potential beneficiaries in future rounds of policies supporting firms' digitalisation.

The rest of the paper is organised as follows: section 2 describes the main characteristics of the Italian National Plan Industry 4.0. Section 3 gives evidence on the use of the 14.0 incentives by Italian firms according to the ISTAT survey on the usage of ICT in the business sector and some recent ad hoc surveys carried out by ISTAT and other institutions. Section 4 analyses the firms' propensity to the digital transformation by adopting an innovative 5-group classification of firms that takes into account both their degree of digitization and their endowment of productive factors. Section 5 shows how the propensity to use the 14.0 incentives is spread across the new classification. Section 6 estimates what factors (beside digitalisation) affect the use of fiscal incentives. Section 7 draws some conclusions.

\section{THE ITALIAN PLAN INDUSTRY 4.0}

Early in 2016 a new industrial policy was designed which led MISE to launch, in February 2017, the Industry 4.0 National Plan (14.0). The new strategy was aimed at integrating some "vertical" measures (mainly focusing on the support to specific sectors or technological areas) with a range of "horizontal" measures (accessible to all firms) with the specific objective to boost the investment in new technologies, as well as in research and development, and to increase the competitiveness of Italian firms (MEF et al. 2017).

In this respect, three criteria have been adopted in designing the policy:

- to implement non-discriminatory measures, i.e. leaving to firms the choice of whether investing or not in new technologies;

- to use almost exclusively indirect incentives, mainly fiscal ones, in order to reduce the administrative burden associated to applications for direct funding;

- to leave firms the choice across a range of different support measures, taking advantage of one or more of the incentives made available by MISE. 
The main goal was that of encouraging Italian firms - mostly those in the manufacturing sector - to replace outdated production equipment with new machinery which could be possibly integrated with advanced digital technologies such as robotics and automation, cloud computing, big data, sensors, 3D printers, etc. The main incentive introduced by MISE was an increased depreciation allowance of the cost of acquisition of machinery embodying 'Industry 4.0' technologies (Nascia and Pianta 2018). In the 2016 Budget Law a distinction was introduced between:

- the increased depreciation allowance for investment in new machinery (as a fixed percentage ${ }^{1}$ of the $140 \%$, rather than the standard $100 \%$, of the cost of the purchased equipment: "superdepreciation") and

- a specific support to investment in Industry 4.0 technologies, i.e. digitally connected devices and related software and services (increased depreciation allowance as a fixed percentage of the $250 \%$, rather than $100 \%$, of the investment spending: "hyper-depreciation").

Such an approach was virtually unprecedented in Italy and, as such, uncertain about its chances to be successful. Additionally, it was soon realised that this specific MISE policy was extremely difficult to be properly monitored and evaluated.

Since all Italian firms were eligible for most of the incentives included in the Plan, the identification - ex-ante - of a specific 'target group' was only a matter of speculation. On the other hand, the use of indirect incentives made it impossible to know whether the acquisition of new technology by a firm had been undertaken with the intention to use the fiscal incentives or not, thus making any on-going monitoring of this measure almost impossible to undertake.

In order to overcome the issue, MISE, also in co-operation with ISTAT and other research institutions, has been actively investigating over the last two years the behaviour of Italian firms about their use of the incentives made available by the I4.0 Plan.

Statistical surveys have been the main tool chosen by MISE in order to get the information needed for designing and monitoring its 14.0 policies. They have included:

- the ISTAT business confidence survey 2017;

- the MET la Rome-based private research centre of economic policy) survey 2017-2018 (MISE-MET 2018);

- the annual ISTAT survey on the usage of Information and Communication Technologies (ICT) by Italian enterprises, 2017.

\section{EVIDENCES FROM STATISTICAL SURVEYS ON THE USE OF INCENTIVES}

\section{THE ISTAT BUSINESS CONFIDENCE SURVEY 2017}

A preliminary evidence on the attitude of Italian firms towards the 14.0 incentives, as well as their use almost two years after the launching, was collected through the ISTAT business confidence survey carried out in November 2017 (ISTAT 2018). The results of such a qualitative survey on a representative sample of around 4,000 manufacturing firms allowed for shedding light on two key issues:

a. the role of incentives in encouraging the firms to invest in new technologies during the period 2015-2017;

b. firms' intentions to further invest in 14.0 technologies in 2018.

As expected, the survey pointed out that the super-depreciation incentive had either a "high" or "moderate" role in influencing the previous years' investment of the majority of Italian manufacturing firms (62.1\%) as an average between $57.3 \%$ of small enterprises (less than 50 persons employed) and $66,9 \%$ of large ones (over 250 persons employed). Hyperdepreciation has been quite influential too: it had a "high" or "moderate" role to convince $53.0 \%$ of firms to invest in digital technologies, ranging from $34.2 \%$ for small firms to $57.6 \%$ for large ones.

When asked about investments planned for 2018 , almost $46 \%$ of the surveyed firms reported the intention to invest in new software, $31.9 \%$ in communication technologies ("machine-to-machine" or internet of things), $27 \%$ in data processing (cloud, mobile, big data etc.) and in IT security. Firms' size emerged, of course, as a key factor influencing investments even though the needs to keep firms up-to-date with the technological progress and to increase the employees' skills (also through the recruiting of new personnel) are additional investments' drivers both in small and in large firms.

\section{THE MET SURVEY 2017-2018}

Another sample survey, covering a population of 23,700 Italian firms including micro-enterprises (less than 10 persons employed) and service firms, was conducted by MET a few months after the ISTAT confidence survey by asking similar questions on the use of 14.0 tax incentives (MISE-MET 2018; Cassa Depositi e Prestiti and MET 2018). The comparison with the ISTAT confidence survey is hardly possible as both the reference population and the scope of the survey (the MET survey covers many different topics) were different. According to the MET survey only $15.2 \%$ of Italian firms asked for super- or hyper-depreciation incentives. This figure is remarkably low and appears to be strongly influenced by the inclusion of micro-enterprises (whose average is $12.1 \%$ ) in the sample. Larger firms behave differently when accessing the mentioned tax incentives which, according to the survey, are indeed used by $32.8 \%$ of small firms ( $10-49$ persons employed) and by $47.5 \%$ of medium and large firms ( 50 persons employed or more). Overall, the MET figures are lower than those produced by ISTAT but it is confirmed that at least $50 \%$ of the largest firms should have profited of available incentives.

\section{THE 2017 ISTAT BUSINESS SURVEY ON THE ICT USAGE}

In addition to the potential use of occasional surveys to collect data for policy monitoring purposes (as in the surveys described above), ISTAT identified the survey on ICT usage in businesses (ICT survey) as the key source to assess the level of digitalisation of Italian firms and, in relation to it, their propensity to use public incentives to increase their technological assets. 
The Italian ISTAT ICT survey is part of the Eurostat's Community survey on ICT usage and e-commerce in enterprises, conducted on an annual basis since 2002, which collects data on the use of information and communication technology and the access to Internet, as well as on e-government, e-business and e-commerce activities, by Italian firms. The scope of the survey includes firms with 10 or more persons employed belonging to a broad range of economic activities. The reference population of the 2017 ISTAT ICT survey included about 185,000 firms whose behaviour has been estimated on the answers given by a realised sample of around 20,000 firms.

The results of the ICT survey are fully integrated in a broader ISTAT database of business data, also including data from other statistical and administrative sources, thus giving a chance for developing new and integrated indicators on the relationships between ICT usage and other features of the firms' activities.

\section{THE DEGREE OF DIGITALISATION OF ITALIAN FIRMS}

In order to support the monitoring of the 14.0 policies, ISTAT has developed an analytical approach, based on the profiling of firms according to their propensity to invest in digital technologies, to gauge if they could be interested or not in accessing the key 14.0 incentives.

A number of economic indicators are indeed available for the whole population of Italian firms by matching basic economic indicators from the Structural Business Statistics (SBS) annual survey and the administrative data, including tax statements, cost statements, balance sheets and firms' reports regularly collected by ISTAT. The realised sample of the Italian ICT survey has been matched with other data sources at micro-level in order to undertake a profiling exercise based on three steps and aimed at classifying the Italian enterprises, with no less than 10 persons employed, according to their propensity to invest in new technologies and to use public incentives for such investments ${ }^{2}$.

The first step has been that of classifying the firms by adopting the indicators identified by Eurostat as essential to describe their level of digitalisation ${ }^{3}$. The Eurostat's Digital Intensity Index, calculated at firm level, has been adopted as the basis for an evaluation of how intense the digital investment by Italian firms is. This classification is, indeed, only a partial one, as it does not include any measure about the size of the technological investment by firms as well as about their ability to fully exploit the potential, in terms of productivity growth, made available by the investment in new technologies.

Then, the second step was that of integrating in the classification exercise an additional set of three digital indicators (all of them derived from the 2017 ISTAT ICT survey) describing the orientation of firms to implement advanced digital technologies (with reference to the period 2014-2016): (1) Investments on Cloud Computing, Web applications or Big Data Analytics; (2) Investments on e-commerce, social media; (3) Investments on Internet of things, addictive printing, robotics, augmented/ virtual reality.

The third step introduced in the analysis two structural indicators about the firm's endowment of productive factors: (1) the availability of fixed capital (measured in terms of the monetary value of tangible and intangible fixed asset per person employed) and (2) the availability of human capital (based on the education and job tenure of the firm's workforce) $)^{4}$.

It is assumed that the propensity to digital transformation might be influenced by the actual availability of fixed and human capital. The endowment (both quantitative and qualitative) of the factors of production (capital and labour) and their distribution among the firms' business functions directly affects productivity but also, indirectly, the digitization strategies. The availability of these indicators allowed for a firms' classification by level of capitalisation and by level of staff qualification.

Table 1. Breakdown of the population of Italian firms with at least 10 employees by degree of digitalisation (percentage). Year 2017.

\begin{tabular}{|c|c|c|}
\hline \multirow[b]{2}{*}{$\begin{array}{l}\text { Degree of } \\
\text { digitalisation }\end{array}$} & \multicolumn{2}{|c|}{ Indicators on fixed capital and workforce } \\
\hline & $\begin{array}{l}\text { Medium-low capitalisation / } \\
\text { medium-low staff qualification }\end{array}$ & $\begin{array}{l}\text { Medium-high capitalisation / } \\
\text { medium-high staff qualification }\end{array}$ \\
\hline Low & \multicolumn{2}{|l|}{ 1. Analogue ( $64.6 \%$ of firms) } \\
\hline Medium & $\begin{array}{l}\text { 2. Potentially digital- } \\
\text { oriented }(20.7 \%)\end{array}$ & 3. Partially digitalised (2.3\%) \\
\hline High & 4. Digital-oriented (9.4\%) & 5. Fully digitalised (3.0\%) \\
\hline
\end{tabular}

The combination of the indicators calculated as a result of the three described steps allowed for a classification of Italian firms according to their propensity to digitalisation (or digital transformation, see Table 1).

As shown in Table 1, five groups of firms have been identified. To the first group, which includes $64.6 \%$ of the population, belong firms with a very low level of digitalisation. The peculiarity of such firms is that in the ISTAT ICT survey they stated that ICT investments are not relevant for their current business activity. They can be seen as being still analogue ones. This group includes more than $90 \%$ of small-sized firms (10-49 persons employed), with a high share of firms belonging to traditional industries (metal products, food products, textiles and clothing, leather, wood), construction, horeca and some business services. The second group, that of potentially digital-oriented firms $(20.7 \%$ of the population), is apparently interested in extending its digital activities but

3 The Digital Intensity Index (DII) is a micro-based index developed by Eurostat to contribute to the EU Commission's monitoring of digital progress that measures the availability at firm level of 12 different digital technologies: (1) Percentage of employees connecting to Internet by PC; (2) Percentage of employees connecting to Internet by mobile devices; (3) Hiring of ICT consultants; (4) Internet connection's average speed; (5) Corporate web-site available; (6) E-commerce available on the corporate web-site; (7) Use of social media; (8) Intensive use of cloud computing; (9) Electronic invoicing; (10) Web advertising; (11) Percentage of online sales on total sales higher than 1\%; (12) Percentage of online B2C sales higher than 10\% of total online sales. The value for the index therefore ranges from 0 (the firm uses none of previous technologies) to 12 (it uses all of them). The DII is a component of the data scoreboard used in the Europe's Digital progress Report (https://ec.europa.eu/digital-single-market/en/news/europes-digital-progress-report-2017 ). A detailed definition of this methodology can be found in ISTAT (2018). 
this process may be hindered by low levels of capitalisation and human capital's qualification. Both SMEs and large firms are included in this group, mainly dealing with trade and manufacturing. The third group is that of the partially digitalised firms (2.3\% of the population) which are units not yet able to complete their process of digitalisation despite their large availability of fixed and human capital. It is indeed quite a small group of firms, mainly belonging to trade and other service industries. The fourth group includes the digital-oriented firms $19.4 \%$ of the population) which are the largest share of firms with a high level of digitisation, but low levels of capitalisation and quality of the workforce. This group outperforms the other groups in terms of profitability. Finally, only $3 \%$ of the Italian firms with 10 persons employed or more are fully digitalised. Not surprisingly, they are the best performers in terms of productivity because of an effective combination of capital and labour.

\section{THE PROPENSITY TO USE THE INCENTIVES}

It could be assumed that the higher the level of digitalisation, the higher the propensity of enterprises to use the incentives made available by the I4.0 Plan. In this perspective, the digitalisation can be seen as a process that builds upon itself by making available assets and competencies to allow for a constant grow. On the other hand, it is also a matter of fact that those firms that are not yet fully digitalised have a higher pressure, and potential, to catch up by using any available support.

These assumptions can be preliminarily tested by taking into consideration the answers given by the firms to the ICT 2017 survey's question about the three most important factors that could make digitalisation a driver of competitiveness and growth. Around $46 \%$ of firms with at least 10 persons employed consider public incentives one of the most important factors supporting the digital transformation but the impact of incentives is differently rated according to the level of digitalisation of recipients. By using the classification described above, Figure 1 provides for a comparison between the firms' attitudes towards public incentives to digitalisation by level of digitalisation. The partially digitalised firms, i.e. those which have in their medium-high level of capitalisation and/ or qualification of employees a key driver to foster the digitalisation processes, are the most interested to receive public incentives (more than $75 \%$ of them). Also the fully digitalised firms are eager to further invest in technology with the support of public incentives (67.3\%). The digital-oriented and the potentially digital-oriented firms are considering incentives less relevant even though the potential beneficiaries within these groups are numerous (respectively, 61\% and 60\%). Apparently, the availability of incentives cannot change the attitude of "analogue" firms towards the investment in digital assets and processes: only $36.9 \%$ of them consider public incentives and funding effective.

By interpreting the results of the 2017 ICT survey as an evidence to be used for an ex-ante assessment of the potential use of fiscal incentives made available by MISE for investments in new machinery and technologies (super-depreciation) or in digital technologies (hyper-depreciation) some hypotheses could be done ${ }^{5}$.

1. With a specific reference to the acquisition of digital technologies in order to increase the level of digitalisation of a firm, public incentives seem to have higher impact on firms partially or fully digitalised - thus, the current degree of digitalisation could have a role in fostering investment in digital technologies.

2. As far as the asset availability is concerned, a medium-high level of capitalisation could encourage firms to exploit the support made available by the government to undergo a digital transformation.

\section{USE OF FISCAL INCENTIVES: THE EVIDENCE}

The results from statistical sources used to estimate the use of 14.0 incentives for the years 2015-2016 have been made available between October 2017 and March 2018. Late in spring 2018, the fiscal data on the actual use of the 14.0 supporting measures were released, for statistical and analytical purposes, by the Italian Tax Agency.

Fiscal data partially confirm statistical estimates ${ }^{6}$.

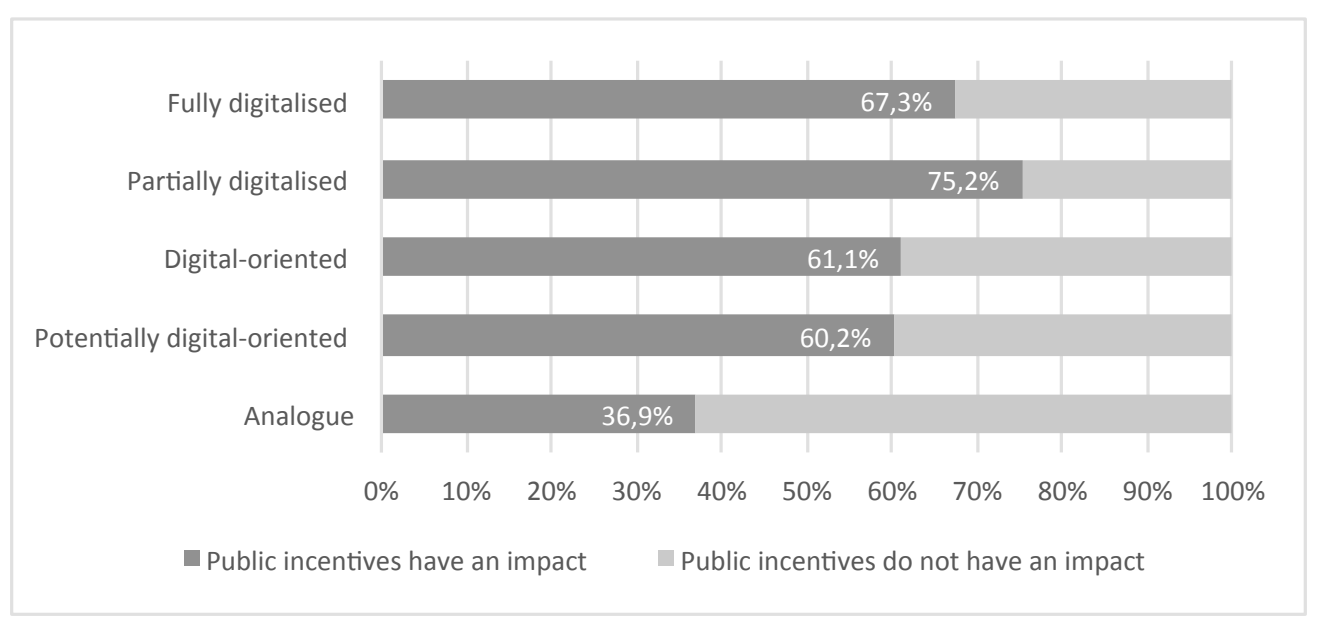

Figure 1. Firms' attitude towards public incentives to digitalisation. Italian ICT survey 2017.

$5 \quad$ Similar results can be found in the analysis by Centro Studi Confindustria (CSC 2018) based on the same set of data.

$6 \quad$ The analysis described in this paper is based on the tax statements of the firms surveyed by the ISTAT 2017 ICT survey in order to allow for comparing statistical and administrative (fiscal) data. In this respect, also sampled fiscal data, appropriately weighted, are representative of those of the population of Italian firms with at least 10 employees. 
As shown in Table 2, the partially digitalised firms have indeed a leading role in the use of fiscal incentives for the acquisition of new technology (61.9\% for super-depreciation and 5.9\% for hyper-depreciation) even though at a lower level than estimated by the 2017 ICT survey (75\% as a combination of both measures).

Not so far, in terms of percentage of beneficiaries, are the digitaloriented and the potentially digital-oriented firms $(54.2 \%$ and $4.4 \%$ for the earlier and $58.8 \%$ and $3.6 \%$ for the latter, both above the average) by highlighting the role of public incentives to help firms to overcome financial and organisational barriers to technological innovation.

About the extreme cases, the fully digitalised firms seem interested in improving their technological capacity $(54.1 \%$ used super-depreciation) but much less oriented (or needed) to get more digital equipment and software (only $2.6 \%$ used hyper-depreciation). Finally, the analogue firms confirm to be relatively reluctant to invest in new technology $145.7 \%$ used super-depreciation, 2.6\% hyper-depreciation). An interesting point is that analogue firms are the only group that was under-estimated in the 2017 ICT survey (Figure 1) about its intention to use fiscal incentives.

Table 2. Percentage of Italian firms using 14.0 incentives for hyper- or super-depreciation. October 2015-December 2016. By digital intensity.

\begin{tabular}{|l|c|c|}
\hline \multicolumn{2}{|c|}{$\begin{array}{l}\text { Percentage of firms investing } \\
\text { in digital technologies } \\
\text { (hyper-depreciation) }\end{array}$} & $\begin{array}{l}\text { Percentage of firms } \\
\text { investing in new machinery } \\
\text { and technologies (super- } \\
\text { depreciation) }\end{array}$ \\
\hline Analogue & 2.6 & 45.7 \\
\hline $\begin{array}{l}\text { Potentially } \\
\text { digital-oriented }\end{array}$ & 3.6 & 58.8 \\
\hline Digital-oriented & 4.4 & 54.2 \\
\hline $\begin{array}{l}\text { Partially } \\
\text { digitalised }\end{array}$ & 5.9 & 61.9 \\
\hline Fully digitalised & 2.6 & 54.1 \\
\hline All & 3.1 & 49.9 \\
\hline
\end{tabular}

The information given in Table 2, focusing on percentages of firms using fiscal incentives, should be qualified by considering the actual size of the investments funded through hyper-and super-depreciation.

In Table 3, the average 14.0 annual depreciation per employee is displayed by comparing the five groups of firms by digital intensity (only applicant firms for the concerned incentive have been taken into consideration). Overall, it could be noticed that an average annual superdepreciation (roughly $140 \%$ of standard depreciation) of about 400 euros per employee corresponds to a total investment - for a firm with $100 \mathrm{em}$ ployees, in a five year time-span - of around 600,000 euros: a substantial amount of money but not really sufficient to support a full restructuring of either a goods or services production line. In this perspective it has to be pointed out that partially digitalised firms, which have the highest percentage of incentives' use, also have, by large, the lowest average per employee expenditure in new technology (263 euros of hyper-depreciation and even 194 euros of super-depreciation).

The fully digitalised firms (at least those using fiscal incentives) have profited more than other groups by these measures with a yearly average of 824 euros of hyper-depreciation and 974 euros of super-depreciation per employee ${ }^{7}$.
Table 3. Average yearly hyper- or super-depreciation per employee. October 2015-December 2016. By digital intensity.

\begin{tabular}{|l|c|c|}
\hline \multicolumn{2}{|c|}{$\begin{array}{l}\text { Average yearly hyper- } \\
\text { depreciation per employee }\end{array}$} & $\begin{array}{c}\text { Average yearly super- } \\
\text { depreciation per employee }\end{array}$ \\
\hline Analogue & 349.2 & 281.3 \\
\hline $\begin{array}{l}\text { Potentially } \\
\text { digital-oriented }\end{array}$ & 266.3 & 296.8 \\
\hline Digital-oriented & 352.1 & 632.5 \\
\hline $\begin{array}{l}\text { Partially } \\
\text { digitalised }\end{array}$ & 263.2 & 194.5 \\
\hline Fully digitalised & 824.0 & 973.8 \\
\hline All & 348.3 & 408.9 \\
\hline
\end{tabular}

Additional information is needed to provide an assessment of the impact of the investments funded through the 14.0 Plan on the fixed capital of the beneficiaries. Preliminary evidence, shown in Table 4 (with reference to the same applicant firms as for Table 3), suggests that this impact could be fairly relevant, although not always sufficient to substantially increase the current capital per employee ratio. When the depreciation reported in the tax statements is compared to the current working capital per employee ratio, a net increase of the latter can be calculated ranging from $0.9 \%$ to $6.8 \%$ assuming, as an average investment, the acquisition of PCs or similar devices (depreciation coefficient of $20 \%$, over 5 years, with hyper-depreciation). On the other hand, if the super-depreciation scheme applies, the increase of the working capital per employee ratio - for the same standard purchase - ranges from 3.8\% to $11.7 \%$.

Table 4. Average percentage increase of working capital per employee for investments with hyper- or super-depreciation. October 2015-December 2016. By digital intensity.

\begin{tabular}{|l|c|c|}
\hline \multicolumn{2}{|c|}{$\begin{array}{l}\text { Average \% increase } \\
\text { of working capital } \\
\text { per employee (hyper- } \\
\text { depreciation) }\end{array}$} & $\begin{array}{l}\text { Average \% increase } \\
\text { of working capital } \\
\text { per employee (super- } \\
\text { depreciation) }\end{array}$ \\
\hline Analogue & 3.5 & 4.6 \\
\hline $\begin{array}{l}\text { Potentially } \\
\text { digital-oriented }\end{array}$ & 5.0 & 11.7 \\
\hline Digital-oriented & 5.4 & 7.1 \\
\hline Partially digitalised & 0.9 & 3.8 \\
\hline Fully digitalised & 6.8 & 6.4 \\
\hline All & 2.6 & 5.7 \\
\hline
\end{tabular}

Some preliminary findings can be drawn from the evidence shown in the tables above. First, the groups of firms by digital intensity are ranked, in terms of actual incentives' use, consistently with the ex-ante estimations although forecasted and actual percentages of beneficiaries do not match exactly. From this perspective, both the ex-ante assessment and the on-going monitoring by using statistical sources have been quite successful.

Second, what was not possible to gauge from the available statistical sources is any forecast about how much investment firms were eager to make. A general comment, based on the available evidence, is that the impact of the 14.0 investments on the endowment of working capital and, even more, on the level of digitalisation, of Italian firms has been, on average, substantial but not disruptive. 


\section{WHICH FACTORS AFFECT THE USE OF FISCAL INCENTIVES?}

\section{THE ROLE OF DIGITALISATION}

Evidence collected so far about the use of 14.0 fiscal incentives reflects, as expected, the high heterogeneity of the Italian business sector. By splitting the population of firms with at least ten persons employed, in five groups by digital intensity such heterogeneity has been partially reduced, as only some very key features (mostly technologically related ones) of firms' activity have been considered in profiling them. This does not exclude that other factors could have affected the firms' strategy as far as the investment in new technologies and the use of fiscal incentives to increase it are concerned.

A multiple regression analysis has been performed in order to compare the propensity of the five digital groups to use fiscal incentives (dependent variable) by excluding any spurious effect due to additional firms' characteristics (independent variables): productivity (value added per employee), capital intensity (working capital per employee), financial leverage (debt to capital ratio), vertical integration (value added/turnover), size (number of persons employed), job tenure of employees (years, average), education of employees (years of study, average), economic activity (2-digit NACE sectors), firm's age (years) and exporter status.

In Figure 2, the propensity to use the super-depreciation in a given measure is estimated for four groups of firms by digital intensity taking the group of analogue firms as a benchmark and any additional feature on a ceteris paribus basis ${ }^{8}$.

The results of the regression confirm that the level of digitalisation and, even more, quantity and quality of fixed capital and human quality, affect the choices of firms about whether investing in new technologies - then using the available incentives - irrespective of size, economic activity or other features. The groups of firms shown in Figure 2, all outperform the benchmark group of analogue firms but, more relevant, the groups with medium-high capitalisation and medium-high workforce qualification have a remarkable advantage in implementing an innovation strategy with public support.

A similar analysis ${ }^{9}$ is shown in Figure 3 with reference to the use of hyper-depreciation, i.e. the use of fiscal incentives to support investments in digital technologies. The overall propensity to use incentives is lower than for the super-depreciation but the pattern of the relationship between the firms' groups is almost the same. In addition to a minor role of analogue firms, those firms with higher capital intensity and workforce qualification display a higher propensity to use the fiscal incentives to digitalisation. It means that, ceteris paribus, a fully digitalised firm will use hyper-depreciation by a factor six times higher than a digital-oriented firm. In this case, the level of digitalisation plays also a role by giving a small advantage to digital-oriented firms on potentially digital-oriented firms and to fully digitalised firms on partially digitalised ones.

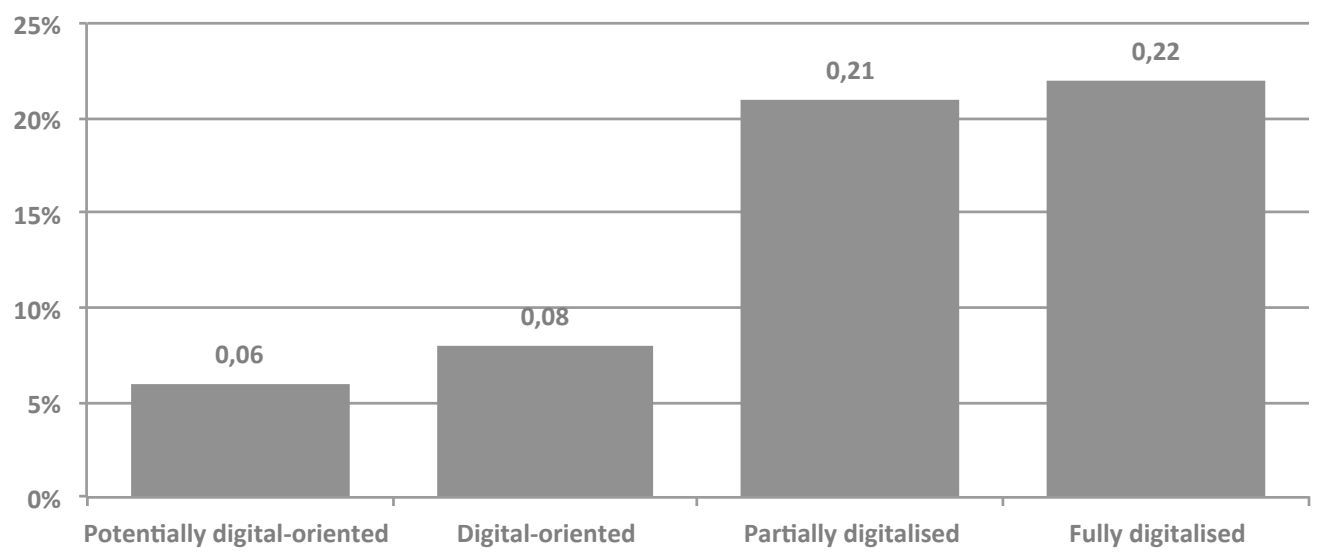

Figure 2. Propensity to use the super-depreciation incentive.

October 2015-December 2016. 


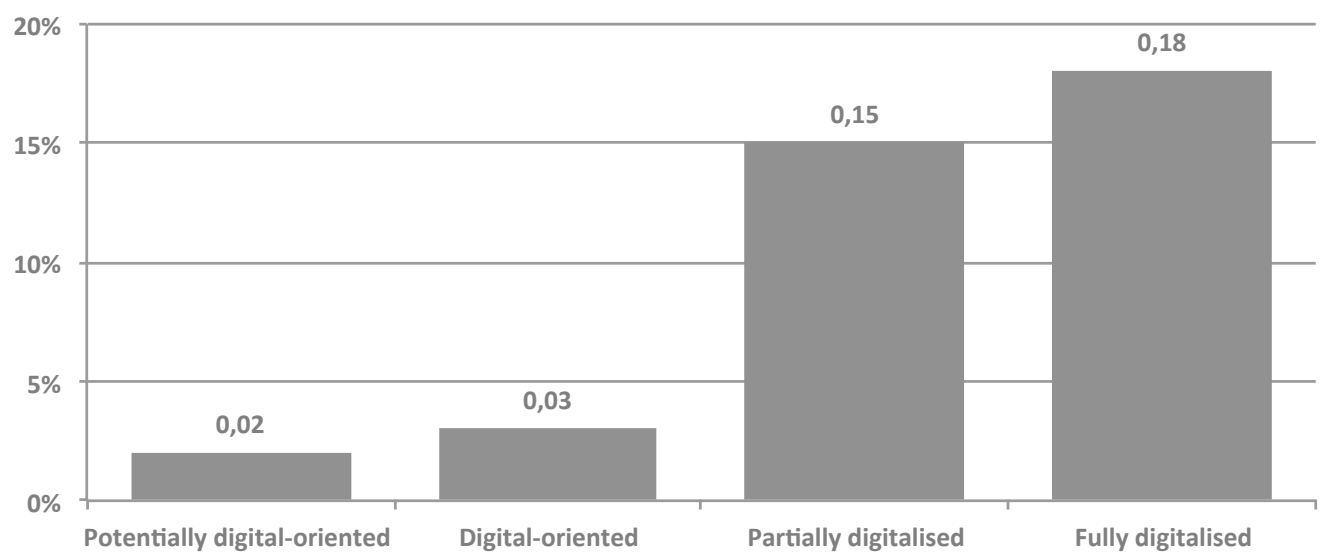

Figure 3. Propensity to use the hyper-depreciation incentive. October 2015-December 2016.

These findings confirm the relevance of the classification by digital intensity proposed in the paper and provide for a new standard in the development of indicators on the digitalisation of the business sector: that of combining data on the use of digital technologies with information on the ability of the firms to effectively use such technologies, i.e. having developed both an appropriate infrastructure and the needed competences. Without these conditions to be fulfilled, even substantial incentives given by the public sector could be ineffective to support the firms' digital transformation.

\section{BEYOND DIGITALISATION}

A further analysis, based on a random forest regression ${ }^{10}$, allows for preliminarily exploring the role of non-digital factors to support the digitalisation of Italian firms through the use of fiscal incentives.

In Figure 4 and in Figure 5, a number of factors are ranked according to their role on framing a context where fiscal incentives can be effectively used by firms. The analysis considers the effect of each factor separately, thus avoiding any combined effect which could have influenced the data presented in previous paragraphs.

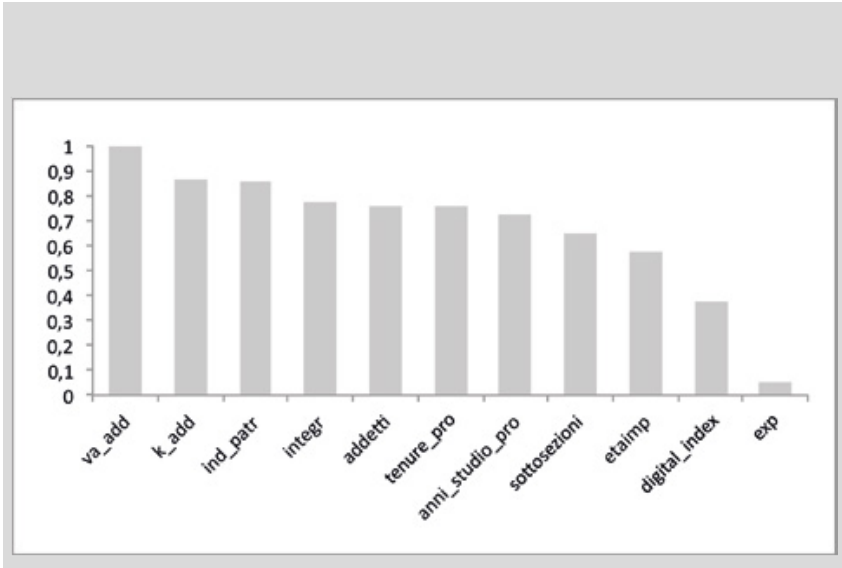

\section{Legend}

\begin{tabular}{|l|l|}
\hline Variable code & Variable name \\
\hline va_add & Productivity (value added /p.e.) \\
\hline k_add & Working capital per employee \\
\hline ind_patr & Debt to capital ratio \\
\hline integr & Vertical integration \\
\hline addetti & Persons employed \\
\hline tenure_pro & Tenure of employees (years, average) \\
\hline anni_studio_pro & Years of study of employees (av) \\
\hline sottosezioni & Economic activity \\
\hline etaimp & Firm's age (years) \\
\hline digital_index & Digital intensity (5 groups) \\
\hline exp & Exporter status \\
\hline
\end{tabular}

Figure 4. Factors moderating the use of fiscal incentives for investment in new machinery (super-depreciation). Year 2016. 
Moreover, those data and analyses have emphasized the role of digital technologies as enablers of the adoption of more digital procedures and associated devices: a dimension not relevant in this new perspective. Finally, random forest is a machine learning algorithm that is not based on a pre-defined model about the role of each factor (variable) or the relationships among them but explores the moderating effect of each factor by selecting it randomly. This approach is very effective in a context where complex interactions among factors can be assumed and any information about their respective role is lacking.

In terms of results, both Figure 4 and Figure 5 show that the key factor influencing the propensity to invest in new technologies, thus to use fiscal incentives to do it, is the labour productivity. The more a firm is productive, the more it has an incentive to further increase efficiency and competitiveness.

Three additional factors strongly influencing the use of fiscal incentives are of structural nature: capital per employee, debt-to-capital ratio and vertical integration ratio. They are, respectively, the second, third and fourth most important factors to affect the use of super-depreciation and the third, fourth and fifth as far as the hyper-depreciation is concerned.

The most striking difference between the two incentives is about the role of the firms' size. Size is the second most important factor for the hyper-depreciation and the fifth for the super-depreciation. It seems that size is a significant condition to undergo a process of digitalisation with relevant investments in new technologies ${ }^{11}$.

The quality of the workforce - both in terms of level of education and seniority at work - is also important for accessing both the incentives, as well as the economic activity.

Least relevant are three factors (for both incentives): the age of the firm, the level of digitalisation and the export propensity.

\section{CONCLUSIONS}

With reference to the question about the ability of statistical systems to provide for a useful knowledge base for designing effective fiscal policies in order to support innovation and digitalisation in the business sector, the answer from this paper is substantially positive. A detailed profiling of firms could allow for the ex-ante identification of groups of potential beneficiaries although additional work has to be done in order to develop suitable methods to improve estimations on the number of potential beneficiaries and on the amount of incentives potentially requested.

Another key issue is that of combining structural, financial and technological variables to identify the key factors enabling a firm to invest in technological innovation or, more specifically, in the digital transformation. Of course, the availability of digital competences is an essential asset but an innovation strategy that includes the acquisition of advanced technologies can be afforded only by an efficient firm with a high level of productivity, high quality workforce and which would be financially sound.

Three main findings of this study can be pointed out:

- The level of digitalisation does not affect the access to incentives, as a consequence, it does not affect the level of investment in new technology.

- Monitoring the use of incentives with surveys is a good starting point but survey results are clearly biased by an optimistic attitude of respondents.

- Technical, financial and human capabilities are the key factors boosting investment in new technologies.

To the extent some preliminary policy lessons could be drawn from the findings above, a few points have to be highlighted.

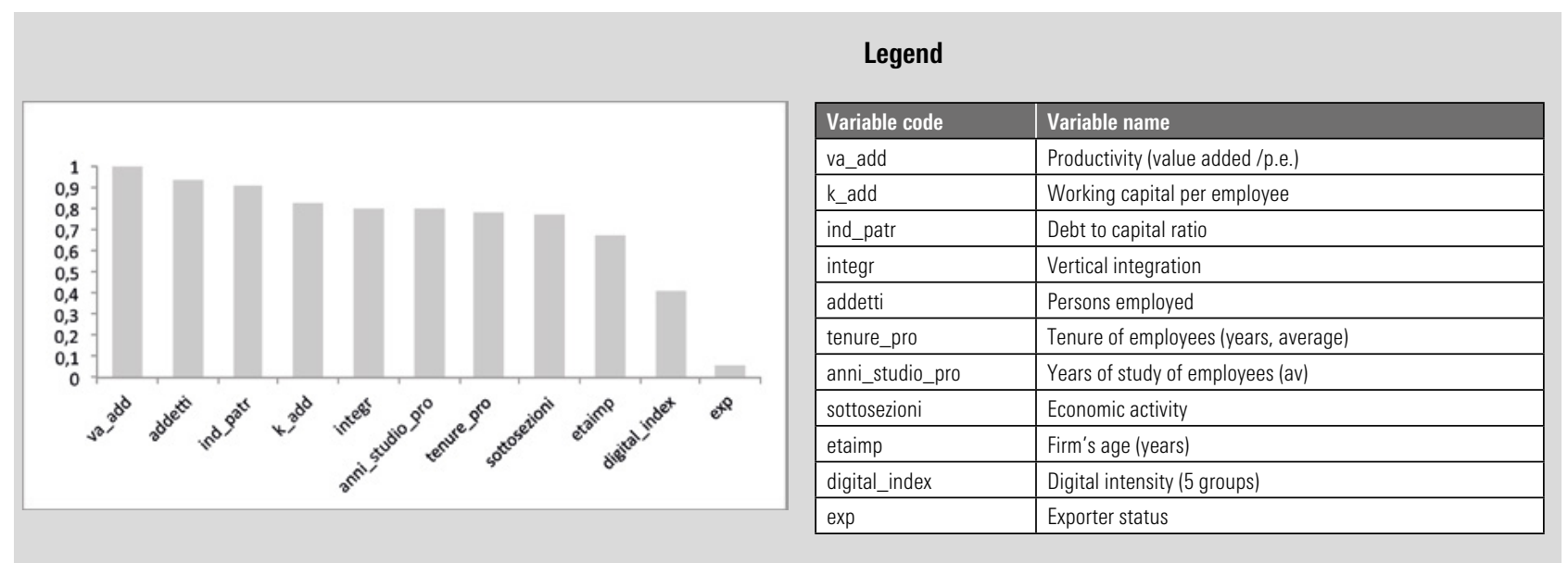

Figure 5. Factors moderating the use of fiscal incentives for investment in digital technologies (hyper-depreciation). Year 2016. 
Digitalisation targets have to realistic and suitable for groups of firms with a very heterogeneous digital and productive structure.

The risk of opening up the access to fiscal (automatic) incentives to every firm is that such incentives could be used as a complementary source of funding for large firms already substantially investing in their digital transformation but, at the same time, as an occasional chance to support the acquisition of selected equipment by small firms or firms without a digitalisation strategy. This reduces substantially the potential impact of the 14.0 measures and call for an urgent intervention.

This raises the issue whether public support had to be mainly given to firms (mostly SMEs) only "potentially" digitalised by adopting the implementation of a two-steps approach: first, supporting the development of capabilities, then funding the digitalisation process.

\section{REFERENCES}

Akaike H. (1974). A new look at the statistical model identification, IEEE Transactions on Automatic Control, 19(6), 716-723.

Arvanitis S and Hollenstein H. (2001). The Determinants Of The Adoption Of Advanced Manufacturing Technology, Economics of Innovation and New Technology, 10:5, 377-414.

Bley, K., Leyh, C. and Schäffer, T. (2016). Digitization of German Enterprises in the Production Sector-Do they know how "digitized" they are? Paper presented at the Twenty-second Americas Conference on Information Systems, San Diego, 2016. https://www.researchgate.net/profile/ Christian_Leyh/publication/305661673_Digitization_of_German_Enterprises_in_the_Production_Sector_-_Do_they_know_how_digitized_ they_are/links/5798c14108aed51475e87572.pdf

Cassa Depositi e Prestiti - MET (2018). II sistema produttivo italiano. Tra modernizzazione e Industria 4.0, Quaderni CDP, n.3.

Centro Studi Confindustria (2018). Imprese e politica insieme per I'industria italiana 4.0, Note CSC, n. 18/03.

Götz M. and Jankowska B. (2017). Clusters and Industry 4.0 - do they fit together?, European Planning Studies, DOI: 10.1080/09654313.2017.1327037.

ISTAT (2018), Rapporto sulla competitività dei settori produttivi, ISTAT, Rome www.istat.it/it/archivio/212438.

MEF (Ministero dell'economia), MISE, MIUR, ML (2017). Piano nazionale IMPRESA 4.0 Risultati 2017-linee guida 2018, September 2017, http://www.sviluppoeconomico.gov.it/images/stories/documenti/impresa_40_risultati_2017_azioni\%202018_rev_eng.pdf.

MISE - MET (2018). La diffusione delle imprese 4.0 e le politiche: evidenze 2017, Rome, Italian Ministry for Economic Development.

Neubig, T. et al. (2016). Fiscal incentives for R\&D and innovation in a diverse world, OECD Taxation Working Papers, No.27, OECD Publishing, Paris.
Nascia L and M. Pianta (2018). Research and innovation policy in Italy, Economia Politica, October 2018.

Rüßmann, M., Lorenz, M., Gerbert, P., Waldner, M., Justus, J., Engel, P. and M. Harnisch, (2015). Industry 4.0: The future of productivity and growth in manufacturing industries. Boston Consulting Group, 9.

Sauter, R., Bode, M. and Kittelberger, D. (2015). How Industry 4.0 is changing how we manage value creation. Horváth \& Partners White Paper, https://www.horvath-partners.com/en/publications/featured-articles-interviews/detail/how-industry-40-is-changing-how-we-managevalue-creation

Tao, F., Oi, 0., Liu, A. and Kusiak, A. (2018). Data-driven smart manufacturing. Journal of Manufacturing Systems, 48/C, 157-169.

ZEW (2015), Industrie 4.0: Digitale (R)Evolution der Wirtschaft, ZEW IKTReport Oktober 2015.

\section{AUTHORS}

\section{GIULIO PERANI}

E: Giulio.Perani@istat.it

STEFANO COSTA

E: Stefano.Costa@istat.it

\section{STEFANO DE SANTIS}

E: Stefano.Desantis@istat.it

Data analysis and economic, social and environmental research, ISTAT Via Cesare Balbo 16, Rome, 00184 (Italy) 